\title{
Comparison of Canadian versus United States emergency department visits for chronic obstructive pulmonary disease exacerbation
}

\author{
Brian H Rowe MD MSc ${ }^{1}$, Rita K Cydulka MD MS², Chu-Lin Tsai MD MPH ${ }^{3,4}$, Sunday Clark MPH ScD ${ }^{4}$, \\ Douglas Sinclair MD FRCPC ${ }^{5}$, Carlos A Camargo Jr MD DrPH ${ }^{3,4}$
}

\begin{abstract}
BH Rowe, RK Cydulka, C-L Tsai, S Clark, D Sinclair, CA Camargo Jr. Comparison of Canadian versus United States emergency department visits for chronic obstructive pulmonary disease exacerbation. Can Respir J 2008;15(6):295-301.
\end{abstract}

INTRODUCTION: Despite the frequency of emergency department (ED) visits for chronic obstructive pulmonary disease (COPD) exacerbation, little is known about practice variation in EDs.

OBJECTIVES: To examine the differences between Canadian and United States (US) COPD patients, and the ED management they receive.

METHODS: A prospective multicentre cohort study was conducted involving 29 EDs in the US and Canada. Using a standard protocol, consecutive ED patients with COPD exacerbations were interviewed, their charts reviewed and a two-week telephone follow-up completed. Comparisons between Canadian and US patients, as well as their treatment and outcomes, were made. Predictors of antibiotic use were determined by multivariate logistic regression.

RESULTS: Of 584 patients who had physician-diagnosed COPD, $397(68 \%)$ were enrolled. Of these, 63 patients (16\%) were from Canada. Canadians were older ( 73 years versus 69 years; $\mathrm{P}=0.002$ ), more often white $(97 \%$ versus $65 \%$; $\mathrm{P}<0.001)$, less educated $(\mathrm{P}=0.003)$ and more commonly insured $(\mathrm{P}<0.001)$ than the US patients. US patients more commonly used the ED for their usual COPD medications ( $17 \%$ versus 3\%; $\mathrm{P}=0.005)$. Although Canadian patients had fewer pack-years of smoking (45 pack-years versus 53 pack-years; $\mathrm{P}=0.001$ ), current $\mathrm{COPD}$ medications and comorbidities were similar. At ED presentation, Canadian patients were more often hypoxic and symptomatic. ED treatment with inhaled betaagonists (approximately 90\%) and systemic corticosteroids (approximately $65 \%$ ) were similar; Canadians received more antibiotics (46\% versus $25 \% ; \mathrm{P}<0.001)$ and other treatments $(29 \%$ versus $11 \%$; $\mathrm{P}=0.002$ ). Admission rates were similar in both countries (approximately 65\%), although Canadian patients remained in the ED longer than the US patients ( $10 \mathrm{~h}$ versus $5 \mathrm{~h}$, respectively; $\mathrm{P}<0.001$ ).

CONCLUSIONS: Overall, patients with acute COPD in Canada and the US appear to have similar history, ED treatment and outcomes; however, Canadian patients are older and receive more aggressive treatment in the ED. In both countries, the prolonged length of stay and high admission rate contribute to the ED overcrowding crisis facing EDs.

Key Words: Canada-USA; Chronic obstructive pulmonary disease; Emergency department; Exacerbation
Une comparaison entre les consultations dans les urgences canadiennes et américaines en raison d'une exacerbation de maladie pulmonaire obstructive chronique

INTRODUCTION : Malgré la fréquence des consultations à l'urgence en raison des exacerbations de maladie pulmonaire obstructive chronique (MPOC), on ne sait pas grand-chose de la variation des pratiques à l'urgence.

OBJECTIFS : Examiner la différence entre les patients canadiens et américains atteints de MPOC et la prise en charge qu'ils reçoivent à l'urgence.

MÉTHODOLOGIE : Les auteurs ont mené une étude de cohorte multicentre prospective auprès de 29 urgences des États-Unis (EU) et du Canada. Au moyen d'un protocole standard, ils ont interviewé des patients consécutifs ayant consulté à l'urgence à cause d'exacerbations de la MPOC, ont analysé leur dossier et effectué un suivi téléphonique au bout de deux semaines. Ils ont comparé les patients canadiens et américains, ainsi que leur traitement et leurs issues. Ils ont déterminé les prédicteurs d'usage d'antibiotiques par régression logistique multivariée.

RÉSULTATS : Des 584 patients atteints d'une MPOC diagnostiquée par un médecin, 397 (68\%) ont participé. De ce nombre, 63 (16\%) provenaient du Canada. Les Canadiens étaient plus âgés (73 ans au lieu de 69; $\mathrm{P}=0,002)$, plus souvent blancs $(97 \%$ par rapport à $65 \% ; \mathrm{P}<0,001)$, moins instruits $(P=0,003)$ et plus souvent assurés $(P<0,001)$ que les patients américains. Les patients américains utilisaient davantage l'urgence pour leur médication habituelle contre la MPOC (17\% par rapport à $3 \% ; \mathrm{P}=0,005)$. Même si les patients canadiens avaient fumé moins de paquets/année (45 paquets/année par rapport à 53 paquets/année; $\mathrm{P}=0,001$ ), la médication courante contre la MPOC et les comorbidités étaient similaires. A leur arrivée à l'urgence, les patients canadiens étaient plus souvent hypoxiques et symptomatiques. Le traitement à l'urgence par bêta-agonistes en aérosol (environ 90 \%) et corticoïdes systémiques (environ $65 \%$ ) était similaire. Les Canadiens recevaient plus d'antibiotiques (46\% par rapport à $25 \% ; \mathrm{P}<0,001)$ et d'autres traitements ( $29 \%$ par rapport à $11 \% ; \mathrm{P}=0,002)$. Les taux d'hospitalisation étaient similaires dans les deux pays (environ $65 \%$ ), même si les patients canadiens demeuraient à l'urgence plus longtemps que les Américains (dix heures par rapport à cinq, $\mathrm{P}<0,001$ ).

CONCLUSIONS : Dans l'ensemble, les patients atteints de MPOC aiguë au Canada et aux ÉU semblent avoir des antécédents, un traitement à l'urgence et des issues similaires. Cependant, les patients canadiens sont plus âgés et reçoivent un traitement plus énergique à l'urgence. Dans les deux pays, le long délai avant d'être vu et les taux d'hospitalisation élevés contribuent au débordement des urgences.

${ }^{1}$ Department of Emergency Medicine, University of Alberta, Edmonton, Alberta; ${ }^{2}$ MetroHealth Medical Center, Case Western Reserve

University, Cleveland, Ohio; ${ }^{3}$ Department of Epidemiology, Harvard School of Public Health; ${ }^{4}$ Department of Emergency Medicine,

Massachusetts General Hospital, Harvard Medical School, Boston, Massachusetts, USA; ${ }^{5}$ Departments of Emergency Medicine and Pediatrics, Dalhousie University, Halifax, Nova Scotia

Correspondence: Dr Brian H Rowe, Department of Emergency Medicine, University of Alberta, 1G1.43 Walter C Mackenzie Centre, 8440-112 Street, Edmonton, Alberta T6G 2B7. Telephone 780-407-6707, fax 780-407-3982, e-mail brian.rowe@ualberta.ca 
C hronic obstructive pulmonary disease (COPD) is a major cause of morbidity and mortality worldwide. COPD is mainly a disease of smokers, and it is the only chronic disease in which mortality rates are increasing (1). In the United States (US), COPD exacerbations are the third most common cause of hospitalization, with an estimated 726,000 hospitalizations in 2000; COPD exacerbation also accounts for approximately 1.5 million emergency department (ED) visits per year (2). Canadian statistics on acute COPD in the ED are less readily available; however, of the 14 million ED visits across Canada (3), if $1.4 \%$ are believed to be for COPD (4), this would represent approximately 196,000 ED visits per year.

The management of acute COPD involves early treatment, identification of the etiology of the exacerbation (ie, upper respiratory tract infection) and recognition of respiratory failure. Medical treatment includes the use of bronchodilators (ie, a short-acting beta-agonist, a short-acting anticholinergic or both) (5), systemic corticosteroids (6), judicious use of $\mathrm{O}_{2}$, antibiotics when indicated (7) and noninvasive ventilation (8) in the event of respiratory failure. At times, intubation and intensive care admission may be required (9).

While there are guidelines for the treatment of stable COPD, they do not focus clearly on ED management and differences among national guidelines exist. Despite attempts to standardize COPD management, there remain wide gaps between what is known and what is practiced (10). Some of these differences may vary from country to country.

The goal of the present multicentre study was to compare patient characteristics, pre-ED management, severity at ED presentation, emergency management and two-week outcomes of patients with COPD in Canadian versus US EDs. Although few multinational comparisons in acute respiratory ED visits have been reported, we recently demonstrated important differences in a variety of patient and treatment factors between Canada and the US for acute asthma visits (11). To our knowledge, this is the first published comparison of Canadian and US ED visits for COPD exacerbations.

\section{METHODS}

\section{Study design}

The present observational study combined data from two prospective cohort studies performed from November 1999 to June 2000, and December 2000 to May 2001, as part of the Multicenter Airway Research Collaboration. The institutional review boards at each of the 29 participating hospitals approved the study, and informed consent was obtained from all participants.

\section{Study setting and population}

The Multicenter Airway Research Collaboration is a division of the Emergency Medicine Network (EMNet, www.emnetusa.org). Details on design and data collection have been previously published (9). In brief, using a standard protocol, investigators at 29 EDs in 15 US states and three Canadian provinces provided $24 \mathrm{~h}$ /day coverage for a median of two weeks. Repeat visits by individual subjects were excluded. All patients were managed at the discretion of the treating physician, and no standardized admission criteria were used. Inclusion criteria were a physician diagnosis of COPD, presentation to the ED for treatment of a COPD exacerbation (defined by increasing shortness of breath, worsening cough or change in sputum production $[1,12-15]), 55$ years of age or older, and the ability to provide informed consent.

\section{Study protocol}

Trained research personnel performed the ED interview and assessed patients' baseline clinical characteristics, COPD history and details of their current COPD exacerbation. Data on ED management and course were obtained by chart review. Follow-up data were collected by telephone interview two weeks after the ED visit. Site investigators reviewed all forms before submission to the EMNet Coordinating Center in Boston (Massachusetts, USA), where they underwent further review by trained personnel and then double data entry.

\section{Measurements}

Hospital admission was defined as an admission to an inpatient unit, observation unit or intensive care unit. Each patient's diagnostic group was based on the following question: "Has a doctor ever said that you have asthma, COPD or chronic bronchitis?" Patients were classified as COPD patients if they reported COPD, emphysema or chronic bronchitis. Patients reporting asthma and fulfilling the definition of COPD were classified as having both COPD and asthma (ie, 'mixed' disease).

\section{Validation set}

To address possible diagnostic misclassification, a validation study was performed involving all patients presenting with asthma or COPD during the study period at three of the sites: Massachusetts General Hospital (Massachusetts, USA), MetroHealth Medical Center (Ohio, USA) and University of Alberta Hospital (Alberta, Canada). Patients were confirmed to have COPD (regardless of asthma diagnosis) if they met both of the following criteria: they stated that a physician had given them a diagnosis of COPD, emphysema or chronic bronchitis; and if on review of their medical records, they had a baseline forced expiratory volume in $1 \mathrm{~s}$ of less than $80 \%$ predicted, a forced expiratory volume in $1 \mathrm{~s} /$ forced vital capacity ratio of less than $70 \%$, or other evidence of COPD (radiologist's interpretation of COPD from chest radiograph or computed tomography scan [eg, obvious bullous disease or hyperinflation with flattening of the diaphragm]). Among the 66 patients who reported doctor-diagnosed COPD, none had contradictory spirometric results. Spirometry, chest radiograph and chest computed tomography scan were not performed (or at least were not available) for all patients; however, $82 \%$ of self-reported cases of COPD were confirmed (16).

Insurance status was categorized as private (commercial or private), Medicaid, other public (all Canadian and Medicare) or none. Primary care provider (PCP) status was assigned on the basis of the following question: "Do you have a primary care provider (such as a family doctor, internist, or nurse practitioner)?" Smoking status was coded as neversmoker, former smoker or current smoker. Pack-years of smoking represented cumulative smoking exposure, which was calculated by multiplying the number of packs per day by the number of years of smoking. Symptom frequency between COPD exacerbations was classified into four levels: no symptoms, some symptoms on some days, some symptoms on most days and symptoms most of the time. Subjective symptoms of a current exacerbation were assessed using the following three questions: "Over the past 24 hours, how often did you experience COPD symptoms?"; "Over the past 24 hours, how 


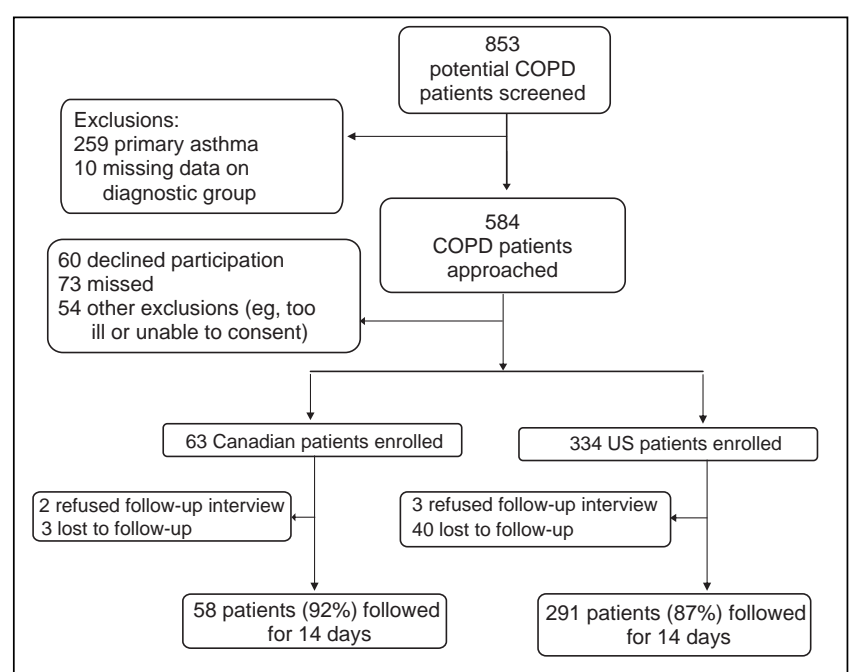

Figure 1) Patient flow diagram for chronic obstructive pulmonary disease (COPD) exacerbation study. US United States

much discomfort or distress have you felt because of these COPD symptoms?"; and "Among all of the activities that you have done over the past 24 hours, how much has your COPD limited you?" The three questions were scored on a four-point scale $(1$, none; and 4 , severe).

Two-week follow-up outcomes were relapse and ongoing exacerbation. Relapse was defined as a worsening of respiratory symptoms that led to an urgent unscheduled clinic visit or ED visit for further care. Ongoing exacerbation during the twoweek follow-up period was assigned to patients who reported 'severe symptoms' during the preceding $24 \mathrm{~h}$ on at least one of two questions (ie, COPD symptoms 'most of the time', or 'severe' discomfort and distress due to their asthma), or who stated that their COPD was 'about the same' or worse than at the time of their ED presentation.

\section{Data analysis}

All analyses were performed using Stata v9.0 software (StataCorp, USA). Data are presented as proportions or medians with interquartile ranges. The associations between Canadian and US baseline clinical characteristics were examined using the $\chi^{2}$ test, Fisher's exact test or Mann-Whitney U test, as appropriate. All $\mathrm{P}$-values are two-sided, with $\mathrm{P}<0.05$ considered statistically significant; however, due to multiple comparisons, comparisons of $\mathrm{P}>0.001$ should be interpreted with caution.

\section{Enrolment}

\section{RESULTS}

Of 853 potential COPD and/or asthma patients screened, 584 had physician-diagnosed COPD (mixed asthma-COPD or COPD only). Of these patients, 397 (68\%) were enrolled. The patient flow is shown in Figure 1. Enrolled and nonenrolled patients were similar across several sociodemographic factors (data not shown) except age, with nonenrolled patients tending to be slightly older than enrolled patients (mean age 73 versus 70 years, respectively; $\mathrm{P}<0.001$ ). Enrolments were similar in Canadian versus US sites (66\% versus 68\%, respectively; $\mathrm{P}=0.59)$. A two-week follow-up was obtained for 349 (88\%) of the enrolled patients. Follow-ups were also similar in Canadian versus US sites ( $92 \%$ versus $87 \%$, respectively; $\mathrm{P}=0.27$ ).
TABLE 1

\begin{tabular}{|c|c|c|c|}
\hline Characteristic & $\begin{array}{l}\text { Canada } \\
(n=5)\end{array}$ & $\begin{array}{l}\text { United States } \\
\quad(n=24)\end{array}$ & $\mathbf{P}$ \\
\hline Public hospital, \% & 100 & 25 & 0.004 \\
\hline $\begin{array}{l}\text { Number of ED visits in one } \\
\text { year, median (IQR) }\end{array}$ & $\begin{array}{c}59,734 \\
(59,495-74,146)\end{array}$ & $\begin{array}{c}64,396 \\
(47,807-76,161)\end{array}$ & 0.91 \\
\hline $\begin{array}{l}\text { Has an emergency medicine } \\
\text { residency program, } \%\end{array}$ & 80 & 96 & 0.32 \\
\hline $\begin{array}{l}\text { Has a designated COPD } \\
\text { treatment area, } \%\end{array}$ & 20 & 26 & 1 \\
\hline $\begin{array}{l}\text { Has a guideline for managing } \\
\text { COPD, } \%\end{array}$ & 20 & 26 & 1 \\
\hline
\end{tabular}

\section{ED characteristics}

Five Canadian and 24 US sites participated in the present study (Table 1). Canadian and US sites were similar according to annual ED volume and having an emergency residency program, designated COPD treatment area or guideline for managing COPD. By contrast, all Canadian sites were public hospitals, whereas only $25 \%$ of US sites were public hospitals.

\section{Pre-ED factors}

Demographic and baseline clinical characteristics are shown in Table 2. The mean $( \pm \mathrm{SD})$ age of the present cohort was $70 \pm 9$ years, and $52 \%$ were women. Sixty-three patients (16\%) were seen in Canadian EDs. Canadian patients were older, more likely to be white, but less likely to have completed high school. Canadian patients were all covered by public health insurance, were more likely to have a PCP, and were less likely to use the ED for their COPD prescriptions. The frequency of health service use in the past year did not differ between Canadian and US patients. Although the distribution of smoking status did not differ between the two groups, the lifetime pack-years of smoking was slightly lower in Canadian patients. Canadian patients were less likely to have mixed diseases, less likely to have taken systemic corticosteroids, and also were less likely to have used inhaled beta-agonists during the preceding month. Canadian and US patients did not differ according to comorbidity status.

\section{ED assessment and treatment}

The severity of the index COPD exacerbation differed between Canadian and US patients (Table 3). Canadian patients reported more frequent and severe COPD symptoms and more severe activity limitation before ED presentation. They also had higher respiratory rates, lower $\mathrm{O}_{2}$ saturations and lower partial pressures of $\mathrm{CO}_{2}$ at ED presentation. The presence of concomitant medical disorder did not differ between the two groups. With respect to ED management, Canadian patients were more likely to receive antibiotics and other adjunct therapies in the ED. While Canadians received more anticholinergics than the US patients ( $86 \%$ versus $76 \%$, respectively; $\mathrm{P}=0.08)$, this difference did not reach significance.

\section{Post-ED outcomes}

With regard to outcomes, Canadian and US patients were equally likely to be admitted overnight to the hospital; however, 
TABLE 2

Demographic and health characteristics of patients presenting to the emergency department (ED) with chronic obstructive pulmonary disease (COPD) exacerbation, according to country

\begin{tabular}{lccc}
\hline Characteristic & $\begin{array}{c}\text { Canada } \\
(\mathbf{n}=63)\end{array}$ & $\begin{array}{c}\text { United States } \\
(\mathbf{n}=\mathbf{3 3 4})\end{array}$ & $\mathbf{P}$ \\
\hline Demographic factors & & & \\
Age, years, mean $\pm \mathrm{SD}$ & $73 \pm 9$ & $69 \pm 9$ & 0.002 \\
Women, \% & 46 & 53 & 0.31 \\
White, \% & 97 & 65 & $<0.001$ \\
High school graduate, \% & 37 & 57 & 0.003 \\
Body mass index, $\mathrm{kg} / \mathrm{m}^{2}$, median $(\mathrm{IQR})$ & 24.7 & 25.0 & 0.56
\end{tabular}

$(21.8-28.4) \quad(21.0-30.0)$

Health care-related factors

Insurance status, \%

Private

Medicaid

Other public

None

Had a primary care provider, \%

ED is the usual site for problem COPD

care, \%

ED is the usual site for COPD

prescriptions, \%

Number of admissions for COPD in

the past year, median (IQR)

Number of urgent clinic visits in the

past year, median (IQR)

Number of ED visits in the past year, median (IQR)

Smoking-related factors

Current smoker, \%

Past smoker, \%

Never-smoker, \%

Pack-years of smoking, median (IQR) 44 (25-56)

Diagnosis

COPD only, \%

Mixed COPD and asthma, \%

Severity of COPD

Duration of COPD history, years,

$8(2-16)$

median (IQR)

Breathing between COPD exacerbations, \%

No symptoms

Some symptoms on some days

Some symptoms on most days

Symptoms most of the time

Ever had an admission for COPD, \%

Ever had intubation for COPD, \%

Ever taken systemic corticosteroids

$$
\text { for COPD, \% }
$$

COPD medication in the past four weeks

Inhaled beta-agonists, \%

Inhaled anticholinergics, \%

Inhaled corticosteroid, \%

Systemic corticosteroid, \%

Long-acting inhaled beta-agonist, \%

Home oxygen use, \%

Antibiotics, \%
60

10

68

68

32

16

$$
29
$$

17

42

12

$89 \quad 0.05$

$53 \quad 0.89$

$17 \quad 0.005$

$0(0-1) \quad 0.65$

$0(0-1)$

0.65

$1(0-4)$$$
0.65
$$

61

9

$54(31-84) \quad<0.001$

$$
54 \quad 0.04
$$

$$
46
$$

$8(4-20) \quad 0.58$

0.42

23

24

TABLE 2 - CONTINUED

Demographic and health characteristics of patients presenting to the emergency department (ED) with chronic obstructive pulmonary disease (COPD) exacerbation, according to country

\begin{tabular}{lccc}
\hline Characteristic & $\begin{array}{c}\text { Canada } \\
(\mathbf{n}=63)\end{array}$ & $\begin{array}{c}\text { United States } \\
(\mathbf{n}=334)\end{array}$ & $\mathbf{P}$ \\
\hline Comorbidities & & & \\
Coronary artery disease, \% & 24 & 22 & 0.69 \\
Congestive heart failure, \% & 22 & 18 & 0.39 \\
History of arrhythmia, \% & 16 & 12 & 0.35 \\
Depression, \% & 10 & 13 & 0.50 \\
\hline
\end{tabular}

IQR Interquartile range

TABLE 3

Emergency department (ED) presentation and clinical course of patients with chronic obstructive pulmonary disease (COPD) exacerbation, according to country

\begin{tabular}{lccc}
\hline & $\begin{array}{c}\text { Canada } \\
(n=63)\end{array}$ & $\begin{array}{c}\text { United States } \\
(n=334)\end{array} \quad P$ \\
\hline Presentation & &
\end{tabular}

ED triage time, $\%$

$\begin{array}{lll}00: 00-07: 59 & 14 & 16 \\ 08: 00-15: 59 & 63 & 59 \\ 16: 00-23: 59 & 21 & 27\end{array}$

Pre-ED arrival condition

Duration of symptom onset, $h, \quad 48(18-108) \quad 48(18-108) \quad 0.17$ median (IQR)

Number of inhaled beta-agonist $\quad 3(0.5-12) \quad 4(1-8)$ puffs within 6 h of ED stay, median (IQR)

Number of inhaled anticholinergic $\quad 2(0-6) \quad 0(0-4) \quad 0.06$ puffs within 6 h of ED stay,

median (IQR)

COPD exacerbation in the past $24 \mathrm{~h}$

Frequency of COPD symptoms, \%

None of the time

$\begin{array}{lll}2 & 3 & 0.004\end{array}$

Some of the time

$17 \quad 27$

Most of the time

All of the time

Severity of COPD symptoms

None

1

Mild

\section{Moderate}

Severe

313

$37 \quad 34$

Activity limitations

None

\section{Mild}

\section{Moderate}

Severe

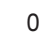

5

0.007

ED presentation

Respiratory rate, breaths/min, $\quad 24(24-28) \quad 24(20-28) \quad 0.03$ median (IQR)

$\mathrm{O}_{2}$ saturation in room air*, \% $89(86-93) \quad 93(90-96) \quad<0.001$ median (IQR)

$\mathrm{FEV}_{1}{ }^{\dagger}, \mathrm{L}$, median $(\mathrm{IQR}) \quad 0.76(0.46-1.15) \quad 0.74(0.5-1.08) \quad 0.84$

$\mathrm{PEF}^{\ddagger}, \mathrm{L} / \mathrm{min}$, median (IQR) $\quad 170(70-180) \quad 149(100-180) \quad 0.96$ 
TABLE 3 - CONTINUED

Emergency department (ED) presentation and clinical course of patients with chronic obstructive pulmonary disease (COPD) exacerbation, according to country

\begin{tabular}{cccc}
\hline & $\begin{array}{c}\text { Canada } \\
(n=63)\end{array}$ & $\begin{array}{c}\text { United States } \\
(n=334)\end{array}$ & $P$ \\
\hline
\end{tabular}

ED presentation - CONTINUED

Arterial blood gas $\$$, mmHg, median (IQR)

\begin{tabular}{|c|c|c|c|}
\hline $\mathrm{pO}_{2}$ & $61(51-70)$ & $68(56-91)^{\pi}$ & 0.03 \\
\hline $\mathrm{pCO}_{2}$ & $42(36-50)$ & $49(42-62)$ & 0.004 \\
\hline \multicolumn{4}{|l|}{ Concomitant medical disorder (\%) } \\
\hline Pneumonia & 18 & 16 & 0.74 \\
\hline Congestive heart failure & 19 & 11 & 0.07 \\
\hline Significant arrhythmia & 5 & 3 & 0.42 \\
\hline Pneumothorax & 0 & 0.3 & 1 \\
\hline \multicolumn{4}{|l|}{ ED course } \\
\hline Given systemic corticosteroids, \% & 65 & 62 & 0.66 \\
\hline $\begin{array}{l}\text { Inhaled beta-agonist treatments - } \\
\text { first hour* }{ }^{* *} \text { median (IQR) }\end{array}$ & $1(0-2)$ & $1(0-2)$ & 0.06 \\
\hline $\begin{array}{l}\text { Total inhaled beta-agonist treatments } \\
\text { in the ED**, median (IQR) }\end{array}$ & $3(2-8)$ & $3(2-3)$ & 0.01 \\
\hline $\begin{array}{l}\text { Inhaled beta-agonist medication in the } \\
\text { ED, \% }\end{array}$ & 89 & 91 & 0.57 \\
\hline $\begin{array}{l}\text { Inhaled anticholinergic treatments - } \\
\text { first hour**, median (IQR) }\end{array}$ & $0(0-1)$ & $1(0-1)$ & 0.38 \\
\hline $\begin{array}{l}\text { Total inhaled anticholinergic treatments } \\
\text { in the ED**, median (IQR) }\end{array}$ & $1(1-4)$ & $1(1-2)$ & 0.004 \\
\hline $\begin{array}{l}\text { Inhaled anticholinergic medication in } \\
\text { the ED }(\%)\end{array}$ & 86 & 76 & 0.08 \\
\hline Received antibiotics in the ED (\%) & 46 & 25 & 0.001 \\
\hline Noninvasive ventilation treatment (\%) & 0 & 4 & 0.24 \\
\hline $\begin{array}{l}\text { Received other COPD treatments in } \\
\text { the } E D^{\dagger \dagger}(\%)\end{array}$ & 29 & 11 & $<0.001$ \\
\hline Intravenous $\mathrm{MgSO}_{4}$ in the $\mathrm{ED}(\%)$ & 6 & 2 & 0.08 \\
\hline
\end{tabular}

*Available for 277 patients; † Available for 42 patients; ${ }^{\ddagger}$ Available for 104 patients; §Available for 113 patients; โSome patients were receiving supplemental oxygen; ${ }^{* *}$ Each nebulizer treatment was counted as equivalent to six puffs from a metered-dose inhaler; ††Other than inhaled short-acting betaagonist, inhaled anticholinergic, systemic corticosteroid, antibiotic treatment

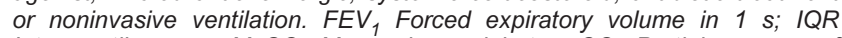
Interquartile range; $\mathrm{MgSO}_{4}$ Magnesium sulphate; $\mathrm{CCO}_{2}$ Partial pressure of carbon dioxide; PEF Peak expiratory flow; $\mathrm{pO}_{2}$ partial pressure of oxygen

Canadian patients had a significantly longer length of stay in the ED (Table 4). On discharge, Canadian and US patients were equally likely to receive systemic corticosteroids and antibiotics. At the two-week follow-up, Canadian and US patients did not differ according to ongoing exacerbations or a relapse requiring acute medical care, except that the relapse rate within $48 \mathrm{~h}$ was higher among the Canadian patients than among the US patients.

\section{DISCUSSION}

The present large, prospective multicentre study is the first to compare Canadian and US ED visits for COPD exacerbations. Overall, patients with COPD exacerbations in Canada and the US appeared to have a similar COPD history, but Canadian patients were older at presentation. Most markers of disease severity at presentation (ie, vital signs, spirometry, need for noninvasive ventilation [8], and so forth) were similar between
TABLE 4

Outcomes, discharge medication and two-week follow-up of emergency department (ED) patients with chronic obstructive pulmonary disease (COPD) exacerbation, according to country

\begin{tabular}{|c|c|c|c|}
\hline & $\begin{array}{l}\text { Canada } \\
(n=63)\end{array}$ & $\begin{array}{l}\text { United States } \\
\quad(n=334)\end{array}$ & $\mathbf{P}$ \\
\hline \multicolumn{4}{|l|}{ ED outcomes } \\
\hline Length of stay, $\mathrm{h}$, median (IQR) & $10(5-21)$ & $5(3-7)$ & $<0.001$ \\
\hline Length of stay $6 \mathrm{~h}$ or greater, \% & 70 & 35 & $<0.001$ \\
\hline Admitted, \% & 67 & 60 & 0.30 \\
\hline $\begin{array}{l}\text { Admitted or ED length of stay greater } \\
\text { than } 6 \mathrm{~h}, \%\end{array}$ & 76 & 66 & 0.13 \\
\hline \multicolumn{4}{|l|}{ Discharge medications } \\
\hline $\begin{array}{l}\text { Sent home on systemic } \\
\text { corticosteroids* } \%\end{array}$ & 57 & 59 & 0.90 \\
\hline Sent home on antibiotics ${ }^{*}, \%$ & 48 & 29 & 0.09 \\
\hline Relapse $^{\dagger}$ & $(n=58)$ & $(\mathrm{n}=291)$ & \\
\hline Relapse within $48 \mathrm{~h}^{\ddagger}, \%$ & 8 & 2 & 0.03 \\
\hline Relapse within two weeks ${ }^{\ddagger}, \%$ & 15 & 18 & 0.62 \\
\hline $\begin{array}{l}\text { Relapse within two weeks leading } \\
\text { to hospital admission§, \% }\end{array}$ & 9 & 12 & 0.77 \\
\hline Ongoing exacerbation $\pi$, \% & 40 & 35 & 0.52 \\
\hline
\end{tabular}

${ }^{*}$ Restricted to patients sent home from the ED ( $\left.n=151\right) ;{ }^{\dagger}$ Restricted to patients available for follow-up ( $n=349)$; $¥$ Relapse event based on patient reporting a 'worsening of COPD symptoms' that led to an urgent care visit; \&Urgent care visit, routine COPD visit or other visit that led to a hospital admission; ISee the Methods section for details. IQR Interquartile range

the groups. Canadians had access to more universal medical coverage, more frequently identified a PCP and less frequently used the ED as their usual source of prescriptions. Both groups appeared to rely on the ED for the delivery of acute COPD care. Despite these observations, the reasons could not be explored in further detail and await additional investigations. The main differences between the countries were with respect to treatment received within the EDs and some variations in discharge therapy; however, there were very little differences between the countries with respect to patient outcomes (both in the ED and during short-term follow-up).

Overall, pre-ED care of COPD was similar, with many patients receiving bronchodilators, 50\% receiving inhaled corticosteroids, and many already initiating preventive treatment for their exacerbation. In general, standard in-ED treatment with corticosteroids and bronchodilators was similar, although Canadian patients received more aggressive therapy (ie, anticholinergics, antibiotics and 'other' agents). This Canadian preference for anticholinergic bronchodilators also was reported in a recent Canada-US comparison of acute asthma care (11). Other care gaps were identified (9); for example, evidence suggests that more antibiotics (7) and corticosteroids (6) should be used in this population, based on their initial severity.

COPD outcomes were similar; in both countries patients received care for extended periods of time and commonly required hospital admission. Both the prolonged length of stay and the high admission rate contribute to the ED overcrowding crisis $(3,17)$. One interesting difference between the two countries is the ED length of stay. In Canadian EDs, patients stayed for prolonged periods, yet the admission proportions were similar across countries. Are Canadian emergency physicians more 
willing to persist longer with ED management in hopes of discharging the patient to home? Alternatively, do Canadian consultants persist with ED-based therapy longer and delay admission because of a lack of either hospital or intensive care unit beds? Whether this is a true between-country difference in 'standard ED care' or 'standard length of ED care' remains unanswered, but merits further study.

Finally, discharge care was similar between the countries for an evidence-based treatment such as systemic corticosteroids (18). By contrast, the use of antibiotics both in the ED and after discharge was more common in Canada (7). Despite these evidence-based treatments, more than one-third of patients would be considered to have failed therapy at the two-week follow-up. For clinicians, this complex disease is difficult to treat, requires close follow-up and perhaps requires home assessments (19) or specialty chronic disease management clinics. In other chronic diseases (ie, coronary artery disease, heart failure), multidisciplinary clinics may be able to more closely monitor disease status, begin rehabilitation, encourage preventive interventions (ie, smoking cessation, immunization, nutrition) and improve outcomes for the most severe cases (20-22).

Current COPD guidelines have not been focused on acute management in the ED. Moreover, there is limited guidance regarding certain issues such as admission criteria. For example, the guidelines recommend that patients with a severe background for COPD should be admitted during an exacerbation; however, the definition is based on spirometric measurements that are rarely collected in the ED. A recent study from this cohort examined admissions to the ED and identified several factors that may assist ED physicians with these complex admission decisions (10). For example, older age, female sex, higher pack-years of smoking, recent use of an inhaled corticosteroid, self-reported activity limitation in the past $24 \mathrm{~h}$, higher respiratory rate at ED presentation and having a concomitant diagnosis of pneumonia increased the likelihood of COPD admission. As this and other new evidence becomes available, it is possible that ED management decisions will become more evidence-based.

\section{LIMITATIONS}

The study has some potential limitations. First, the ED sample is not representative of all North American EDs. It is a volunteer, convenience sample of ED sites that over-represents the academic, urban, inner-city setting and socioeconomically disadvantaged patients, especially in the US sample. While we recognize this, efforts to secure a more balanced representation were not successful. It is likely, however, that these are some of the most interested ED sites in both countries, and this sample may overestimate the quality of care received by North American COPD patients in the ED.

Second, the data were collected by volunteer medical personnel, some of whom had limited research experience. Site research assistant training, a simplified data collection form, ED physician supervision, and data review by the site physician were all performed in an effort to decrease information bias. Third, these data are now somewhat dated and the management of COPD may have changed since the conclusion of data collection in late 2001. For example, these results may have changed somewhat with the recent introduction of long-acting beta-agonists and long-acting anticholinergics to the COPD pharmacopeia. In addition, the introduction of innovative approaches, such as action plans (23), self-management clinics and home hospitalization (19), may have changed since the end of the present study. While we recognize this possibility, these observations were made during the same time frame in both countries, thus maintaining the integrity of the comparisons. Future research will be required to determine whether the observed gaps in care have improved since these data were collected. Finally, this sample is under-represented by Canadian patients $(n=63)$ and sites $(n=5)$. Although the small sample size should reduce the chance of identifying differences, we identified a number of major differences. Moreover, because the Canadian sites are representative of other urban/academic EDs, we believe the conclusions are sound.

\section{CONCLUSIONS}

This comparison of Canadian and US ED care revealed differences between the countries with respect to access to health care and certain management choices for COPD exacerbations; however, the outcomes remain remarkably similar. Given the relative paucity of research on COPD exacerbations, the present study illustrates the gaps between practice and evidence in both countries with respect to COPD treatment $(9,24)$.

ACKNOWLEDGEMENTS: The authors thank the EMNet investigators for their ongoing dedication to public health research, with an emphasis on the treatment and prevention of respiratory/allergy emergencies.

EMNet Steering Committee: Michelle P Blanda, MD; Edwin D Boudreaux, PhD; Carlos A Camargo Jr, MD (Chair); Theodore J Gaeta, DO MPH; Susan Key, RN MS CEN; Jonathan M Mansbach, MD; Steven Polevoi, MD; Michael S Radeos, MD MPH; and Benjamin C Sun, MD MPP.

EMNet Coordinating Center: Christina Ahn; Carlos A Camargo Jr, MD (Director); Sunday Clark, MPH ScD; Kate Delaney; Lisa A Dubois; Adit A Ginde, MD; Andrea J Pelletier, MS MPH; Ashley F Sullivan, MS MPH; Chu-Lin Tsai, MD MPH - all at Massachusetts General Hospital, Boston, Massachusetts, USA.

Principal investigators at the 29 participating sites: FC Baker III (Maine Medical Center, Portland, Maine); MP Blanda (Summa Health System, Akron, Ohio); ED Boudreaux (Earl K Long Memorial Hospital, Baton Rouge, Louisiana); BE Brenner (The Brooklyn Hospital Center, Brooklyn, New York); CA Camargo Jr (Massachusetts General Hospital, Boston, Massachusetts); RK Cydulka (MetroHealth Medical Center, Cleveland, Ohio); TJ Gaeta (New York Methodist Hospital, Brooklyn, New York); B Goldfeder (Shands Hospital at the University of Florida, Gainesville, Florida); RJ Grant (Hartford Hospital, Hartford, Connecticut); RO Gray (Hennepin County Medical Center, Minneapolis, Minnesota); A Guttman (Sir Mortimer B Davis Jewish General Hospital, Montreal, Quebec); LW Kreplick (Christ Hospital \& Medical Center, Oak Lawn, Illinois); DS Mackey (Lethbridge Regional Hospital, Lethbridge, Alberta); A Mangione (Albert Einstein Medical Center, Philadelphia, Pennsylvania); J Peters (University of Texas Health Sciences Center at San Antonio, San Antonio, Texas); MS Radeos (Lincoln Medical Center, Bronx, New York); PL Rice (Brigham and Women's Hospital, Boston, Massachusetts); BH Rowe (University of Alberta Hospital, Edmonton, Alberta); M Sama (St Joseph Mercy Hospital, Ann Arbor, Michigan); D Schreiber (Stanford University Medical Center, Stanford, California); NI Shapiro (Beth Israel Deaconess Medical Center, Boston, Massachusetts); PC Shukla (University of Texas Southwestern Medical Center, Dallas, Texas); D Sinclair (Queen Elizabeth II Health Science Centre (Halifax, Nova Scotia); H Smithline (Baystate Medical Center, Springfield, Massachusetts); PE Sokolove (UC Davis Medical Center, Sacramento, California); 
M Steffens (Palmetto Richland Memorial Hospital, Columbia, South Carolina); CA Terregino (Cooper Hospital/University Medical Center, Camden, New Jersey); A Travers (Royal Alexandria Hospital, Edmonton, Alberta); and EJ Weber (UCSF Medical Center, San Francisco, California).

FUNDING: Dr Rowe's research is supported by the Government of Canada through the 21st Century Research Chairs Program. The study was partially funded by a grant from the Institute for United States Policy Studies (IUSPS) at the University of Alberta.

Presented at the Society of Academic Emergency Medicine Meeting in 2004 and the Canadian Association of Emergency Physicians Meeting in 2004.

\section{REFERENCES}

1. Pauwels RA, Buist AS, Calverley PM, Jenins CR, Hurd SS. Global strategy for the diagnosis, management, and prevention of chronic obstructive disease. NHLBI/WHO Global initiative for chronic obstructive lung disease (GOLD) workshop summary. Am J Respir Crit Care Med 2001;163:1256-76.

2. Mannino DM, Homa DM, Akinbami LJ, Ford ES, Redd SC. Chronic obstructive pulmonary disease surveillance - United States, 1971-2000. MMWR Surveill Summ 2002;51:1-16.

3. Understanding Emergency Department Wait Times: Who is Using Emergency Departments and How Long Are They Waiting? Ottawa: Canadian Institute for Health Information, 2005.

4. Spooner CH, Yiannakoulias N, Holroyd B, et al. Emergency department presentations of chronic obstructive pulmonary disease in Alberta. Can J Emerg Med 2001;3:124.

5. McCrory DC, Brown CD. Anticholinergic bronchodilators versus beta2-sympathomimetics for acute exacerbations of chronic pulmonary disease. Cochrane Database Syst Rev 2002:CD003900.

6. Wood-Baker R, Walters EH, Gibson PG. Oral corticosteroids for acute exacerbations of chronic obstructive pulmonary disease. Cochrane Database Syst Rev 2005:CD005374.

7. Saint S, Bent S, Vittinghoff E, Grady D. Antibiotics in chronic obstructive pulmonary disease exacerbations. A meta-analysis. JAMA 1995;273:957-60.

8. Ram FS, Picot J, Lightowler JV, Wedzicha JA. Non-invasive positive pressure ventilation for treatment of respiratory failure due to exacerbations of chronic obstructive pulmonary disease. Cochrane Database Syst Rev 2004:CD004104.

9. Cydulka RK, Rowe BH, Clark S, Emerman CL, Camargo CA Jr; MARC Investigators. Emergency department management of acute exacerbations of chronic obstructive pulmonary disease in the elderly: the Multicenter Airway Research Collaboration. J Am Geriatr Soc 2003;51:908-16.

10. Tsai C-L, Clark S, Cydulka RK, Rowe BH, Camargo CA. Factors associated with hospital admission among emergency department patients with chronic obstructive pulmonary disease exacerbation. Acad Emerg Med 2007;14:6-14.

11. Rowe BH, Bota GW, Clark S, Camargo CA Jr; for the MARC Investigators. Comparison of Canadian versus American emergency department visits for acute asthma. Can Respir J 2007;14:331-7.

12. American Thoracic Society. Standards for the diagnosis and care of patients with chronic obstructive pulmonary disease. Am J Respir Crit Care Med 1995;152:S77-121.

13. COPD Guidelines Group of the Standards of Care Committee of the BTS. BTS guidelines for the management of chronic obstructive pulmonary disease. Thorax 1997;52(Sppl 5):S1-S28.

14. O'Donnell DE, Aaron S, Bourbeau J, et al. Canadian Thoracic Society recommendations for management of chronic obstructive pulmonary disease - 2007 update. Can Respir J 2007;14(Suppl B):5B-32B.

15. Siafakas NM, Vermeire P, Pride NB, et al. Optimal assessment and management of chronic obstructive pulmonary disease (COPD). The European Respiratory Society Task Force. Eur Respir J 1995;8:1398-420.

16. Radeos MS, Cydulka RK, Rowe BH, Barr RG, Camargo CA Jr. Validation of clinical diagnosis of COPD among patients presenting to the emergency department. Am J Respir Crit Care Med 2001;163:A912.

17. Derlet RW, Richards JR. Overcrowding in the nation's emergency departments: Complex causes and disturbing effects. Ann Emerg Med 2000;35:63-8.

18. Aaron S, Vandemheen K, Hebert P, et al. Outpatient oral prednisone after emergency treatment of chronic obstructive pulmonary disease. N Engl J Med 2003;348:2618-25.

19. Smith B, Appleton S, Adams R, Southcott A, Ruffin R. Home care by outreach nursing for chronic obstructive pulmonary disease. Cochrane Database Syst Rev 2001:CD000994.

20. Clark AM, Hartling L, Vandermeer B, McAlister FA. Meta-analysis: Secondary prevention programs for patients with coronary artery disease. Ann Intern Med 2005;143:659-72.

21. Ahmed A. Quality and outcomes of heart failure care in older adults: Role of multidisciplinary disease management programs. J Am Geriatr Soc 2002;50:1590-3.

22. McAlister FA, Lawson FM, Teo KK, Armstrong PW. A systematic review of randomized trials of disease management programs in heart failure. Am J Med 2001;110:378-84.

23. AC Turnock, EH Walters, JAE Walters, R Wood-Baker. Action plans for chronic obstructive pulmonary disease. Cochrane Database Syst Rev 2005:CD005074.

24. Smithline HA, Rowe BH, Radeos MS, Cydulka RK, Camargo CA Jr. Research opportunities in the management of acute exacerbations of chronic obstructive pulmonary disease. Acad Emerg Med 2005; $12: 742-50$. 


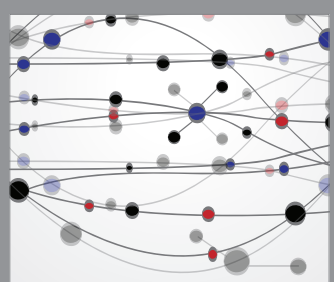

The Scientific World Journal
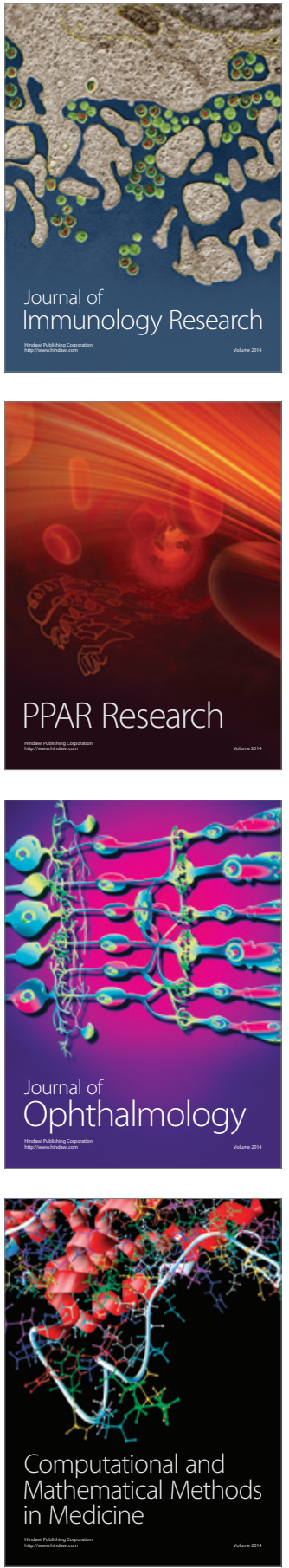

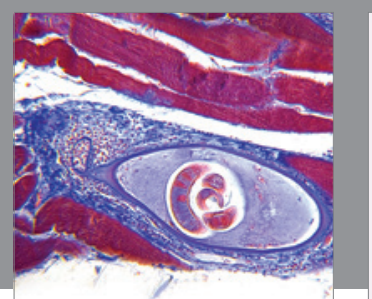

Gastroenterology Research and Practice

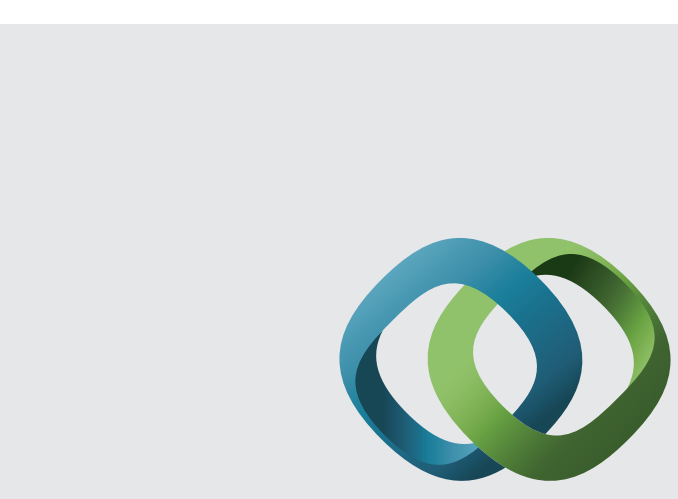

\section{Hindawi}

Submit your manuscripts at

http://www.hindawi.com
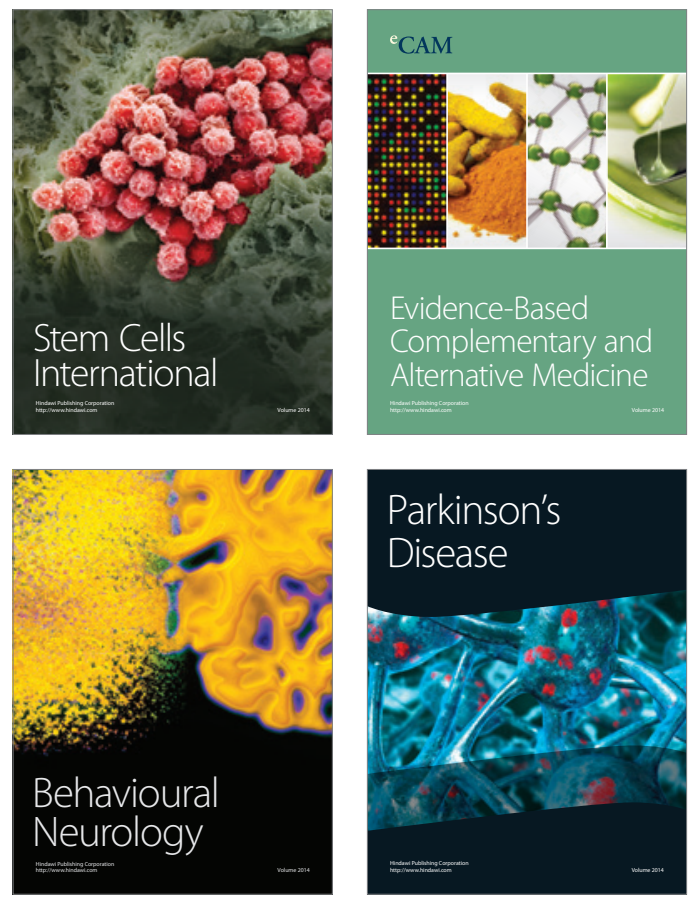
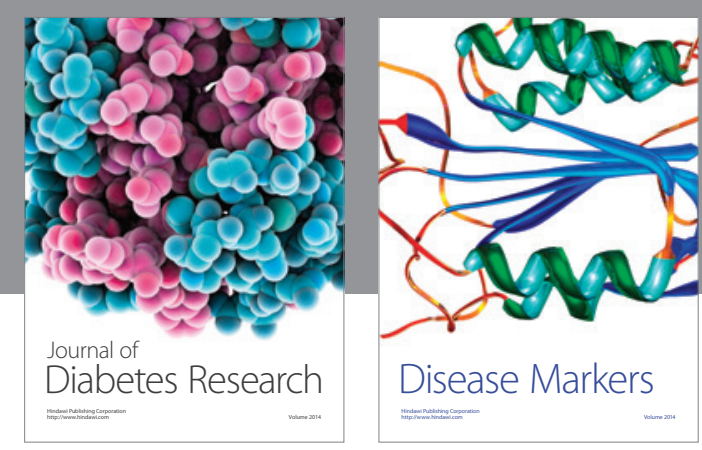

Disease Markers
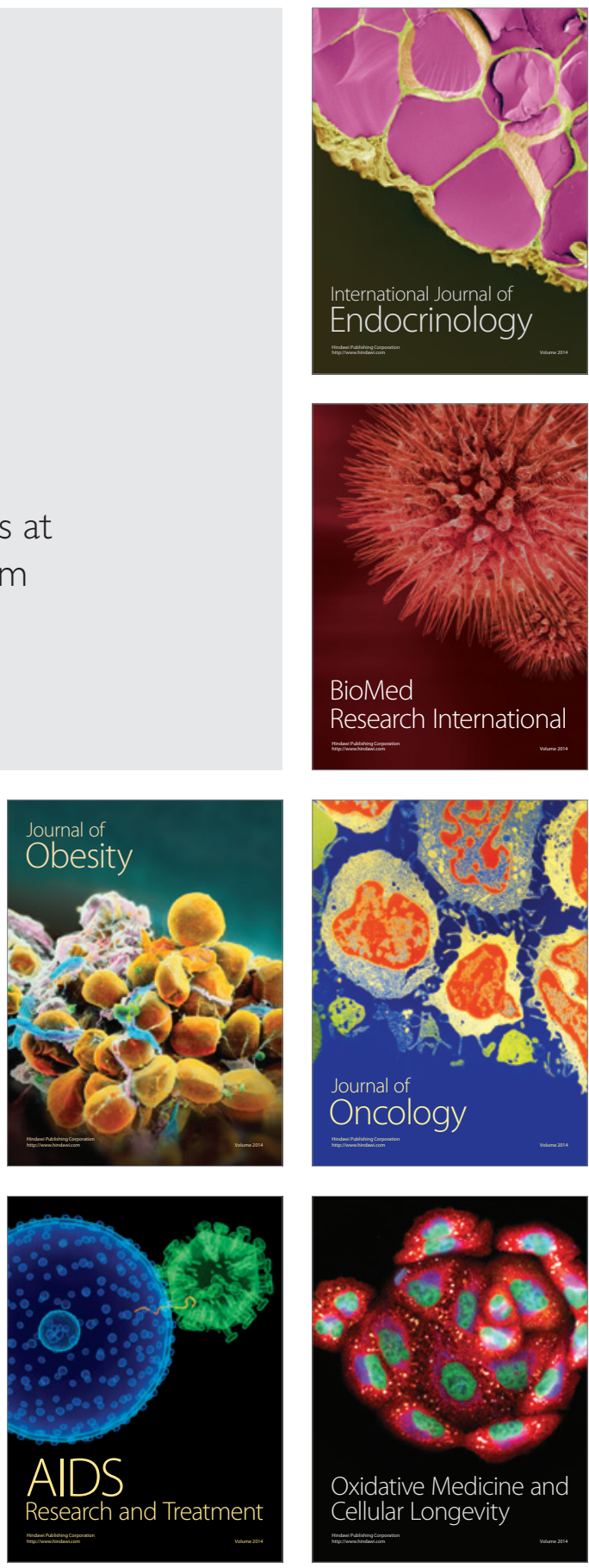